\title{
KLUSTERING DENGAN K-MEANS BERBASIS LVQ DAN K-MEANS BERBASIS OWA
}

\author{
Dian Eka Ratnawati ${ }^{1}$, Indriati ${ }^{2}$ \\ ${ }^{1,2}$ Program Studi Informatika/Ilmu Komputer ,Fakultas Ilmu Komputer \\ Universitas Brawijaya \\ Email: ${ }^{1}$ dian_ilkom@ub.ac.id, ${ }^{2}$ indriati.tif@ub.ac.id
}

(Naskah masuk: 29 Januari 2015, diterima untuk diterbitkan: 17 Februari 2015)

\begin{abstract}
Abstrak
Pada penelitian ini dilakukan pembandingan hasil klustering pada data car evaluation dengan menggunakan KMeans berbasis LVQ (Learning Vector Quantization) dan K-Means berbasis OWA (Ordered Weighted Averaging). Pada kedua metode ini sama-sama mempergunakan K-Means tetapi yang sudah mengalami modifikasi.

Hasil dari penelitian sebelumnya secara terpisah yang membandingkan metode K-Means modifikasi tersebut dengan K-Means konvensional menunjukkan bahwa kedua metode modifikasi tersebut sama-sama lebih baik daripada K-Means konvensional. Tetapi belum pernah ada penelitian yang membandingkan akurasi hasil klustering kedua metode modifikasi tersebut. Sehingga pada penelitian ini dilakukan klustering dengan menggunakan kedua metode tersebut untuk data car evaluation, karena dari penelitian sebelumnya kedua metode tersebut cukup handal dalam melakukan klustering. Hasil dari ujicoba menunjukkan rata-rata hasil akurasi dimulai yang tertinggi adalah K-Means berbasis LVQ(86.50\%), K-Means berbasis OWA $(86,16 \%)$ kemudian K-Means konvensional (56,50\%). Tetapi dengan urutan atribut yang benar dan pemilihan nilai alpha yang tepat yakni 0.8, K-Means berbasis OWA bisa menghasilkan akurasi yang lebih tinggi yakni $93.33 \%$.
\end{abstract}

Kata kunci: K-Means berbasis LVQ, K-Means, K-Means berbasis OWA, bobot

\begin{abstract}
In this paper do a comparison with the results of klustering using K-Means based LVQ (Learning Vector Quantization) and K-Means based OWA (Ordered Weighted Averaging). In both of these methods used K-Means but which has been modified.

Results from previous studies have shown that both methods are better than conventional K-Means. But there has never been a study comparing the accuracy of klustering results of the two methods. So in this study conducted klustering using both methods for data car evaluation, because of previous studies both methods are reliable enough to perform klustering In the researchs before it, both method are prefer than conventionalKMeans, but there are no researchs which compare them. So, in the research, we will compare it by using same data that is car evaluation. In order to know what it is method is the best. The result of research are that in the average , K-Means $\operatorname{LVQ}(86.50 \%)$ is more accuracy than $K$-Means - OWA(86,16\%) and conventional KMeans(56,50). But if the order of selection attributes and alpha values is correct , $K$ Means based OWA can generate higher accuracy that is $93.33 \%$ using the alpha value of 0.8
\end{abstract}

Keywords: K-Means based LVQ, K-Means, K-Means based OWA, weight

\section{PENDAHULUAN}

K-Means konvensional selain mempunyai kelebihan yakni sangat cepat dalam proses klustering, mempunyai beberapa kelemahan antara lain: memungkinkan suatu kluster tidak mempunyai anggota dan hasil klusteringnya selalu berubahubah. Hal tersebut yang melatarbelakangi munculnya berbagai metode K-Means modifikasi. Dua diantaranya dari K-Means modifikasi tersebut adalah K-Means berbasis LVQ dan K-Means berbasis OWA.
Untuk K-Means berbasis LVQ yang akan dilakukan adalah : Pertama : memodifikasi dari KMeans konvensional, yakni melakukan proses $\mathrm{K}$ Means secara iterative sampai nilai threshold tertentu, jika pada threshold tersebut belum didapatkan 1 kluster dengan anggota yang sama, maka baru dilakukan proses LVQ (Learning Vector Quantization). Dengan menggunakan data breastcancer-wisconsin hasil klustering dengan K-Means berbasis LVQ mempunyai tingkat akurasi (92,67\%), yang jauh di atas K-Means konvensional dengan tingkat akurasi : $60.2 \%$. Hal ini menunjukkan dengan data tersebut, K-Means modifikasi 
mempunyai akurasi yang lebih tinggi daripada $\mathrm{K}$ Means konvensional.

Sedangkan K-Means berbasis OWA (Ordered Weighted Averaging) diperkenalkan oleh Cheng dkk (2009) yang melakukan klustering nilai agregat, yang merupakan kumpulan dari nilai multi atribut yang ada. Metode ini berbeda dengan metode K-Means yang telah ada sebelumnya. Cheng dkk (2009) lebih fokus pada cara untuk mengurangi kompleksitas data set eksperimental dan keterkaitan antara berbagai kriteria yang ada, yang dapat diatasi dengan cara menggabungkan K-Means dengan OWA. Dari penelitian yang dilakukan oleh Ulya yang dipergunakan untuk klustering iris menunjukkan metode ini lebih bagus akurasinya dibandingkan dengan K-Means konvensional, yakni K- Means berbasis OWA akurasinya : 96.67 sedangkan K-Means konvensional 89.33.

Dengan melihat keunggulan kedua metode tersebut jika dibandingkan dengan K-Means konvensional, maka pada penelitian ini akan dibandingkan akurasi dari kedua metode modifikasi tersebut yakni K-Means berbasis LVQ dan K-Means berbasis OWA.

\section{TINJAUAN PUSTAKA}

2.1. K-Means berbasis LVQ

Flowchart untuk K-Means berbasis LVQ bisa dilihat pada Gambar 1.

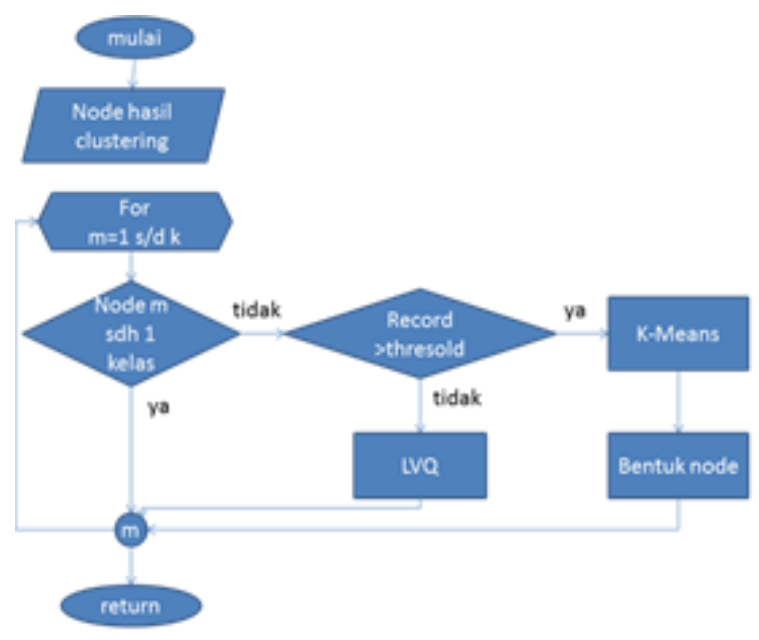

Gambar 1. Flowchart K-Means berbasis LVQ

Seperti pada Gambar 1, tahapan untuk melakukan klustering dengan K-Means berbasis LVQ adalah :

1. Mengelompokkan data dengan metode $K$-Means

2. Dilakukan pengecekan label terhadap semua kelompok yang dihasilkan dari proses K-Means sebelumnya. Yakni apakah anggota pada satu kluster tersebut sudah berlabel sama atau belum. Jika sudah berlabel sama (satu kelas semua), maka pemrosesan terhadap kluster tersebut berhenti, jika tidak lakukan pengecekan ke langkah 3
3. Bandingkan isi kluster dengan threshold (isi minimal anggota suatu kluster). Jika isi kluster > threshold maka dilakukan K-Means lagi, sedang jika $<$ threshold dilakukan LVQ.

\subsection{K- Means berbasis OWA}

Langkah yang dilakukan untuk K-Means berbasis OWA adalah (Cheng, 2007) :

1. Pemilihan Fitur. Pada dataset car evaluation ini ada 6 fitur yang dipilih.

2. Menghitung bobot dengan menggunakan Operator OWA . Algoritma untuk pembobotan dengan OWA mengacu pada Cheng, 2007.

3. Penghitungan nilai agregat berdasar operator OWA dari bobot OWA

4. Kluster nilai agregat . K-Means digunakan untuk menghasilkan kluster yang didasarkan pada nilai-nilai agregat.

5. Prediksi klustering. Dari langkah 4 diperoleh bobot optimal, kemudian dari bobot itu akan dilakukan prediksi klustering terhadap data uji, dengan persamaan (1) :

$$
E_{-} D i s t i=\sqrt{\left(C i_{\text {center }}-a i j\right)^{2}}
$$

\subsection{Pembobotan dengan OWA}

Algoritma untuk metode OWA seperti terlihat pada Gambar 2

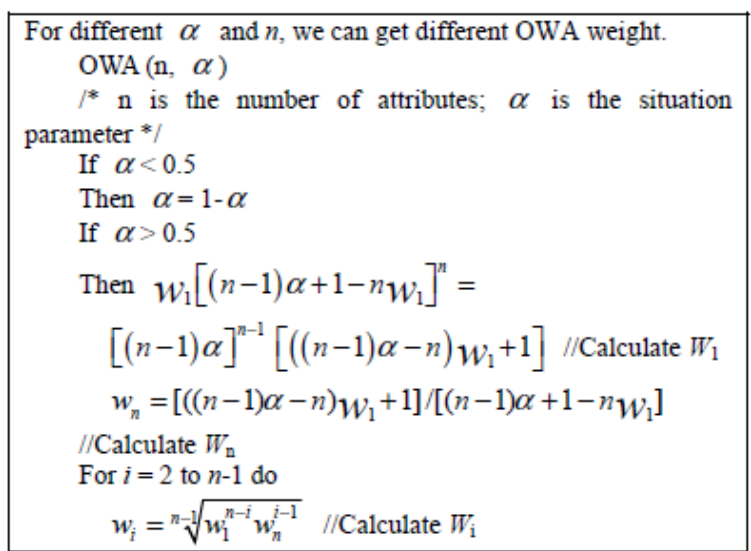

Gambar 2. Algoritma untuk pembobotan dengan OWA. Sumber : Cheng, 2007

\section{Dataset}

Penelitian ini akan menggunakan data car evaluation. Data ini diambil dari website dengan alamat http://archive.ics.uci.edu/ml/dataset/ car+evaluation. Jumlah data tersebut 1728. Dari data tersebut diambil 200 record secara acak sebagai data latih dan 60 record sebagai data uji. Data tersebut memiliki 8 atribut, yaitu :

1. id : nomor data

2. buying: dapat bernilai vhigh, high, med, low.

3. maint: dapat bernilai vhigh, high, med, low. 
4. doors: dapat bernilai 2, 3, 4, 5more.

5. persons: dapat bernilai 2,4 , more.

6. lug_boot: dapat bernilai small, med, big.

7. safety: dapat bernilai low, med, high.

8. class : kelas data, dapat bernilai unacc, acc, good, vgood

Atribut nomor 1 dan no 8 tidak dipakai pada penelitian.

\section{Hasil Uji Coba dan Analisa}

Pada penelitian ini dilakukan dua skenario ujicoba terhadap data car evaluation dengan jumlah data uji 60. Skenario pertama, uji coba dilakukan dengan menggunakan metode K-Means berbasis OWA. Skenario kedua akan membandingkan hasil uji coba antara K-Means berbasis LVQ, K-Means berbasis OWA dan K-Means konvensional dengan menggunakan parameter terbaik pada masingmasing metode.

4.1. Hasil Uji coba dengan menggunakan KMeans berbasis OWA

Ada 2 hal yang ingin diketahui dari uji coba pertama ini : Pertama untuk mengetahui apakah urutan atribut berpengaruh terhadap hasil akurasi. Jika berpengaruh berarti bobot dari setiap atribut seharusnya tidak sama. Kedua untuk mengetahui apakah nilai alpha yang merupakan salah satu parameter dari OWA berpengaruh terhadap hasil akurasi.

Untuk point yang kedua, maka pada uji coba dipergunakan nilai alpha 0.7 dan 0,8 . Hal ini dengan pertimbangan nilai alpha 0.7 dan 0.8 adalah paling baik dari semua nilai alpha antara 0 dan 1 yang sebelumnya telah dilakukan uji coba terlebih dahulu. Hasil ujicoba bisa dilihat pada Tabel.1 dan Gambar 3

Tabel 1. Hasil Ujicoba K-Means OWA terhadap nilai alpha

\begin{tabular}{|c|c|c|r|}
\hline Uji ke & Kombinasi & alpha 0.7 & alpha 0.8 \\
\hline 1 & 150432 & $91.66 \%$ & $90.00 \%$ \\
\hline 2 & 104532 & $85.00 \%$ & $83.33 \%$ \\
\hline 3 & 14325 & $83.33 \%$ & $81.66 \%$ \\
\hline 4 & 150324 & $86.66 \%$ & $83.33 \%$ \\
\hline 5 & 150423 & $91.66 \%$ & $93.33 \%$ \\
\hline 6 & 150324 & $86.66 \%$ & $85.00 \%$ \\
\hline 7 & 12453 & $85.00 \%$ & $83.33 \%$ \\
\hline 8 & 103452 & $81.66 \%$ & $80.00 \%$ \\
\hline 9 & 15423 & $83.33 \%$ & $83.33 \%$ \\
\hline 10 & 154230 & $83.33 \%$ & $85.00 \%$ \\
\hline Rata2 & & $85.83 \%$ & $84.83 \%$ \\
\hline
\end{tabular}

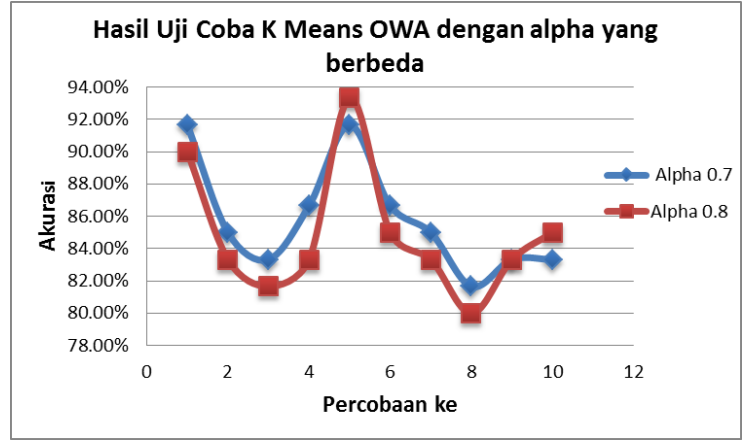

Gambar 3. Hasil Uji coba K-Means OWA dengan nilai alpha yang berbeda

Seperti terlihat pada Tabel 1 dan Gambar 3 menunjukkan bahwa nilai alpha dan urutan atribut mempengaruhi hasil akurasi. Secara rata-rata hasil akurasi dengan menggunakan parameter nilai alpha 0,7 lebih baik $(85,83 \%)$ daripada dengan menggunakan nilai alpha 0,8 yang mempunyai hasil akurasi $84,83 \%$ meski tidak berbeda terlalu jauh.

Dari Tabel 1 dan Gambar 2 terlihat urutan kombinasi atribut yang mempunyai akurasi tertinggi adalah 150423 dengan akurasi $91.66 \%$ (alpha 0.7) dan $93.33 \%$ (alpha 0.8). Rata-rata akurasi untuk urutan 150423 adalah $92.50 \%$. Arti urutan 150423 berarti susunan atributnya adalah maint(1), safety(5), buying(0), lug_boot(4), doors(2) dan persons(3). Susunan tersebut menunjukkan urutan dari bobot, semakin ke kanan maka bobotnya akan semakin tinggi. Sehingga karena atribut maint berada di paling kiri atau posisi pertama, berarti atribut maint mempunyai bobot paling rendah dari kelima atribut yang ada, sedangkan atribut persons karena berada di posisi terakhir berarti mempunyai bobot paling tinggi.

Urutan berikutnya adalah 150432 dengan akurasi $91.66 \%$ (alpha 0.7) dan 90.00\% (alpha 0.8). Rata-rata akurasi untuk urutan 150423 adalah 90.83\%.

Dari hasil uji coba di atas bisa disimpulkan bahwa untuk data car evaluation setiap atribut mempunyai bobot yang berbeda. Pembobotan yang berbeda ini menunjukkan bahwa ada atribut yang sangat berpengaruh terhadap penentuan kluster, sementara ada atribut lain yang kurang berpengaruh. Hanya dengan uji coba bisa diketahui atribut mana yang paling dominan perannya. Dari data tersebut nilai alpha yang paling bagus adalah 0.7 dan 0.8 , meski secara rata-rata nilai alpha 0.7 sedikit lebih unggul daripada alpha 0.8 .

\subsection{Hasil Ujicoba K-Means LVQ, K-Means OWA dan K-Means konvensional}

Untuk skenario uji coba yang kedua ini ingin mengetahui perbandingan ke 3 metode dari segi akurasi dan waktu komputasi. Pada penelitian ini dilakukan 10 kali ujicoba. Hasil uji coba bisa 
dilihat pada Tabel 2 dan Gambar 4. Parameter yang dipergunakan untuk uji coba K-Means berbasis LVQ adalah diambil parameter yang menghasilkan akurasi tinggi, dimana :

Parameter K-Means

- Jumlah kluster : 4,

- $\quad$ threshold :25

Parameter untuk atribut LVQ :

error minimum : 0.000001

Max epoh : 100

Learning rate : 0.05

- $\quad$ Faktor pengurang : 0,01

Selanjutnya hasil terbaik dari setiap metode dapat dilihat seperti pada Tabel 2 dan Gambar 3.

Tabel 2 Hasil uji coba penelitian dengan $K$-Means berbasis OWA, $K$-Means berbasis LVQ dan $K$ Means konvensional

\begin{tabular}{|c|c|c|c|}
\hline Uji ke & K-Means & K-Means & K-Means \\
\hline & LVQ & OWA & murni \\
\hline 1 & $85.00 \%$ & $91.66 \%$ & $58.33 \%$ \\
\hline 2 & $86.66 \%$ & $85.00 \%$ & $53.33 \%$ \\
\hline 3 & $88.33 \%$ & $83.33 \%$ & $33.33 \%$ \\
\hline 4 & $86.66 \%$ & $86.66 \%$ & $73.33 \%$ \\
\hline 5 & $90.00 \%$ & $93.33 \%$ & $60.00 \%$ \\
\hline 6 & $86.66 \%$ & $86.66 \%$ & $65.00 \%$ \\
\hline 7 & $83.33 \%$ & $85.00 \%$ & $53.33 \%$ \\
\hline 8 & $85.00 \%$ & $81.66 \%$ & $66.66 \%$ \\
\hline 9 & $86.66 \%$ & $83.33 \%$ & $55.00 \%$ \\
\hline 10 & $86.66 \%$ & $85.00 \%$ & $46.66 \%$ \\
\hline Rata 2 & $86.50 \%$ & $86.16 \%$ & $56.50 \%$ \\
\hline
\end{tabular}

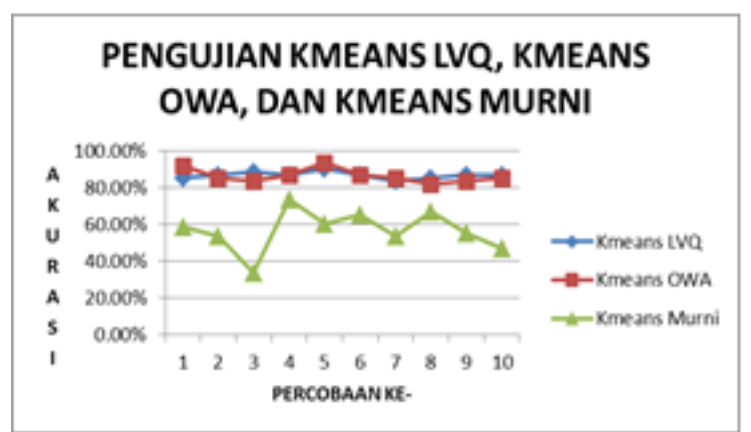

Gambar 4. Hasil uji coba penelitian dengan $K$ Means berbasis OWA, $K$-Means berbasis LVQ dan $K$-Means konvensional

Dari hasil uji coba yang ada pada Tabel 2 dan Gambar 4 menunjukkan bahwa hasil akurasi dari KMeans berbasis OWA dan K-Means berbasis LVQ masih lebih unggul dibandingkan dengan K-Means konvensional. Dengan data car evaluation, K-Means konvensional mempunyai rata-rata akurasi dibawah $60 \%$, yakni $56,50 \%$, sedangkan K-Means berbasis OWA mempunyai rata-rata akurasi $86,16 \%$ dan K-
Means berbasis LVQ mempunyai rata-rata akurasi $86.50 \%$. Rata-rata akurasi tertinggi ada pada metode K-Means berbasis LVQ meski selisihnya hanya $0,34 \%$.

Tetapi dengan urutan atribut yang benar dan pemilihan nilai alpha yang tepat, $K$-Means berbasis OWA bisa menghasilkan akurasi yang lebih tinggi yakni $93.33 \%$. Hal yang menyebabkan K-Means berbasis OWA bisa menghasilkan akurasi yang lebih tinggi daripada K-Means berbasis LVQ dan KMeans konvensional adalah karena K-Means berbasis OWA membedakan bobot antara atribut satu dengan atribut lainnya. Sedangkan untuk KMeans berbasis LVQ dan K-Means konvensional semua atribut dianggap mempunyai bobot yang sama.

Berarti untuk data car evaluation lebih cocok jika mempergunakan metode K-Means berbasis OWA, dimana setiap atribut memiliki bobot yang berbeda. Kelemahan dari metode ini adalah harus dicari semua kombinasi dari sejumlah atribut yang ada, semakin banyak atribut semakin banyak uji coba yang dilakukan. Jadi pertimbangan untuk mempergunakan metode mana yang lebih sesuai tergantung data yang dipakai, apakah memang ada perbedaan bobot terhadap data tersebut atau tidak.

Untuk waktu komputasi, urutan waktu dari yang paling cepat adalah K-Means konvensional, KMeans berbasis OWA, kemudian K-Means berbasis LVQ. K-Means konvensional paling cepat karena bobot dari setiap atribut dianggap sama jadi tidak perlu dilakukan pembobotan terlebih dahulu pada setiap atributnya, langsung dilakukan klustering dengan menggunakan K-Means. Berbeda untuk KMeans berbasis OWA, sebelum dilakukan klustering dengan menggunakan K-Means maka setiap atribut diberikan bobot yang berbeda. Untuk pembobotannya dengan menggunakan metode OWA. Sedangkan untuk K-Means berbasis LVQ waktu komputasinya paling lama. Hal ini karena proses untuk klustering dengan menggunakan KMeans nya sendiri dilakukan secara berulang-ulang hingga mencapai threshold tertentu. Setelah mencapai threshold masih dilakukan pengecekan ulang terhadap isi klusternya apakah sudah selesai atau perlu dilakukan klasifikasi dengan menggunakan metode LVQ.

\section{Kesimpulan}

Dari penelitian ini bisa diambil kesimpulan :

Dengan menggunakan dataset car evaluation rata-rata hasil akurasi dimulai yang tertinggi adalah K-Means $\quad L V Q(86.50 \%), \quad K$-Means berbasis OWA $(86,16 \%) \quad$ kemudian K-Means konvensional(56,50\%). Tetapi dengan urutan atribut yang benar dan pemilihan nilai alpha yang tepat, KMeans berbasis OWA bisa menghasilkan akurasi yang lebih tinggi yakni $93.33 \%$ dengan menggunakan nilai alpha 0.8. Dari segi waktu 
komputasi, K-Means konvensional mempunyai waktu yang paling cepat dibanding metode K-Means modifikasi.

\section{Daftar Pustaka:}

AHN BS. 2006. On The Properties of OWA Operator Weights Functions with Constant Level of Orness, IEEE Transactions on Fuzzy Systems (4),511-515.

CHENG, CHING-HUSE, JING-WEI LIU, MINGCHANG WU,2007. Owa Based Information Fusion Techniques For Classification Problem, Proceedings of the Sixth International Conference on Machine Learning and Cybernetics, Hong Kong, 1922 August 2007, -4244-0973-X/07/\$25.00 C)2007 IEEE.

CHENG CH, JW WANG, DAN MC WU. 2009. OWA-Weighted Based Klustering Method for Classification Problem, Expert Systems with Application4988-4995.

FAYYAD, USAMA., dkk., 1996. From Data Mining to Knowledge Discovery in Databases. American Association for Artificial Intelligence.

FAUSETT, L., 1994, Fundamentals of NeuralNetwork, Architecture, Algorithms and Applications, Prentice Hall, New Jersey

KANTARDZIC, MEHMED. 2003. Data Mining : Concepts, Models, Methods and Algorithm. John Wiley \& Sons. New York.

RATNAWATI, DIAN, MARJI, LAILIL M. 2012. Pengembangan Metode Klasifikasi berdasarkan K-Means dan LVQ, Penelitian DIPA 2012.

RATNAWATI, DIAN, MARJI, 2014. Klustering dengan K-Means dan K-Means modifikasi , proceeding KNSI 2014.

ULYA, MILYATUL, 2011. Modifikasi K-Means Berbasis Ordered Weighted Averaging (Owa) Untuk Kasus Klastering, AGROINTEK Volume 5, No.2 Agustus 2011 